\title{
Performed Experiment Unit Allocation
}

National Cancer Institute

\section{Source}

National Cancer Institute. Performed Experiment Unit Allocation. NCI Thesaurus. Code C153131.

The completed action that is the assignment of an experimental unit to a portion of the study, such as an arm or a portion of an arm (when secondary allocations may occur). 